\title{
Design of the Optimal Geometry of the Moulded Piece Based on Numerical Analyses in Cadmould 3D-F
}

\author{
Paweł Piotr Mańko', Łukasz Majewski ${ }^{*}$ \\ 1 Department of Technology and Polymer Processing, Faculty of Mechanical Engineering, Lublin University of \\ Technology, Nadbystrzycka 36, 20-618, Lublin, Poland \\ * Corresponding author's e-mail:I.majewski@pollub.pl
}

\begin{abstract}
The subject of the work was the assessment of the possibility of using Cadmould 3D-F® software based on numerical analysis to design complex injection moulding cavities with plasticised polymer feed channels on the example of an element requiring special dimensional accuracy. The overarching goal of the design process was to create the most advantageous geometry of the injection moulding cavity model and the dedicated material supply channels, which will minimize the effect of problems occurring during injection moulding process, such as processing shrinkage, surface collapse, warpage and mouldings deformation. As an additional criterion, the smallest possible degree of complexity of the designed system was adopted for economical reasons and elimination of subsequent production problems resulting from the complex geometry of the designed mould.
\end{abstract}

Keywords: injection moulding, filling problems, finite element method, cavity, runners.

\section{INTRODUCTION}

Injection moulding as a manufacturing method is a complex process that is labour-intensive and requires major expenditure, especially during the start-up of a production line. In order to obtain the expected product quality, broad knowledge on the characteristics of polymer processing - from the moment of the occurrence of the demand for a new element to its implementation on the market [13] - is necessary. Polymer processing requires extensive knowledge on the whole process and the material properties [10] in order to consciously and economically modify polymers. Computer simulations of the process are applied to lower the costs. Moreover, such action enables one to accelerate the stages of construction, analysis, verification and validation of the objects, machines and their parts as well as he manufacturing processes. Numerical analyses allow for limiting the time of the research on the accurateness of the designed product as well as for diagnosing and eliminating the problems connected to the process as early as at the design stage. Analyses significantly facilitate the optimization of the process parameters and product geometry $[5,8]$.

\section{The notion of computer simulation}

Computer simulation is a process performing the respectively planned stages of the algorithm in order to approximately investigate the behaviour of a given phenomenon or model in given conditions. Usually real processes are the subject of an analysis, though purely hypothetical models can also be analysed [6]. Using the program allows one to assume the parameters as unchangeable, which would prove very difficult in the real conditions. It is caused by the imperfection of the measuring equipment and random noise occurring during the process, e.g. change to the humidity, temperature or electric current and voltage in the electricity network. Computer simulations enable one to conduct experiments in the quantity impossible or almost impossible in real conditions due to the labour-intensity and major 
expenditure required for the research. Assuming the analysis of a process with 7 parameters, each of which assigned with three variability levels, nearly 2200 experiments $\left(3^{7}=2187\right)$. Conducting such a number of experiments would be timeconsuming and require a lot of expenditure [12]. In order to obtain reliable results, the general rules for design and performance of simulations ought to be followed [11]:

- Formulation of the problem;

- Design of a mathematical model;

- Writing a program for the computer or introducing a model with boundary conditions;

- Verifying the correctness of the model and introduced parameters;

- Planning and performing a series of experiments;

- An analysis of the results.

During the numerical analyses either several versions of the model or the optimisation of the process, based on subsequent results of the analyses ought to be prepared in order to properly conduct the process, obtain reliable results and select the most optimal geometry [17].

\section{Testing model}

In the testing models mirroring a certain process or phenomenon are used. In the case of creating a model physically recreating a process a physical model will be created, whereas a mathematical model will be described by mathematical dependencies. A general scheme of a model is illustrated by Fig. 1. A mathematical model includes the most important parameters describing the most vital aspects of the process. It is necessary to describe the way in which the model is to react to the entered data, which is why often interdisciplinary knowledge of the analysed aspect is necessary $[1,3,4,14]$.

The way in which the model reacts to the introduced parameters is described by the function expressing the dependency between variables,

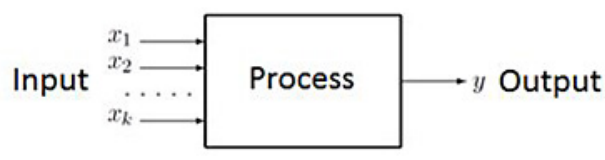

Fig. 1. Scheme of the mathematical model with $\mathrm{k}$-numerous input parameters $(\mathrm{x} 1, \mathrm{x} 2 \ldots \mathrm{xk})$ and the output value $\mathrm{y}[4]$ algebraic operators, differential operators etc. All of those functions and operators have a mutual name of the process. The output value, usually the variable sought throughout the research is called the result or the object response.

The structure of each model is encumbered with error due to certain estimated data values, called the uncertainty of measurement. It is vital to be aware of this problem in order to properly analyse the results. It is also important to allow for a certain correction in the calculations. Compensation is a quantitative identification of the measure of the matching error and reducing the influence of this error on the result $[15,16]$.

\section{Subject and aim of the research}

The subject of the research was spatial geometry in the form of a puzzle piece. A possibility of joining single puzzle pieces into larger structures, as shown in Fig. 2, is assumed. Upon performing adequate analyses, production of an insert to a mould will be commissioned. Further on an experimental verification of the results of a simulation will be conducted. The main aim of the production process was creating a model of the best geometry, which will minimise the effects of the problems occurring during the production process, that is shrink, sink marks, warpage and deformation of the element. Due to economic aspects and elimination of production problems caused by overly complex geometry of the element it is vital to keep the mould as simple as possible.

The issue of geometry optimisation required the element to be modelled and a numerical analysis of the process of polymer injection moulding (polypropylene- ADSTIF EA648P). On the basis of the results of the injection moulding simulation in CADMOULD 3D-F® software changes to the geometry were introduced due to the problems indicated in the simulation (among others significant sink marks, problem with ejecting the piece from the mould and shrink). The models were created in Solid Edge ST10 software.

During the simulations the following parameters were recorded:

- Problem with mould filling;

- Probability of sink marks

- Values and areas of excessive shrink.

The models created in Solid Edge were exported to the extension supported by Cadmould 


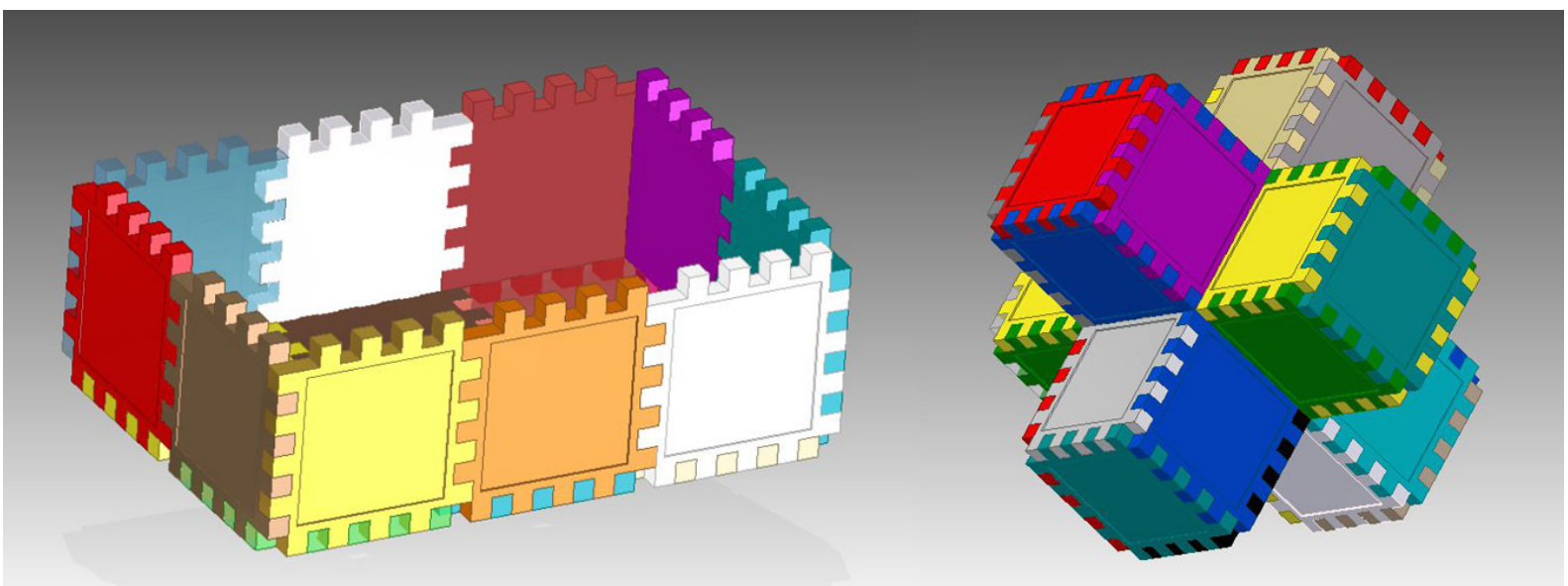

Fig. 2. Box made of puzzle pieces (at left) and Spatial structure made of puzzle pieces (at right)

3D-F - stl, where the following operations were performed:

- Tuning of the model (introducing the scale of the real model);

- FEM mesh generating;

- Selection of materials for injection moulding;

- Introducing process parameters;

- Creating runners and cooling systems;

- Defining the gate.

After performing the aforementioned operations, the injection moulding process was simulated.

\section{Conditions of the injection moulding process simulation}

Due to the changeable geometry of the investigated model, the process parameters, runner and cooling systems were assumed to be unchangeable. This will allow one to compare the modelled model geometries on the basis of the selected parameters. Since these models include two different sets of teeth ( 4 or 7 teeth per wall) the gates are located in slightly different areas while their distribution remains similar.

\section{Runners}

In the simulation a system of runners using a module of the CADMOULD 3D-F® software (Fig. 3) was created, later on applied for all the models while maintaining the same diameters of runners and gates.

In the process of designing runners a concept of creating them using CAD software and exporting to CADMOULD 3D-F® (Fig. 4) was introduced. This action would allow one to obtain valuable information on shrink and deformations both in the piece and the frame created of the polymer consolidated in the runners.

Due to the lack of knowledge or information in specialist literature on hybrid joining of runners made in CADMOULD $3 \mathrm{D}-\mathrm{F}{ }^{\circledR}$ with the runners created in CAD software in this simulation

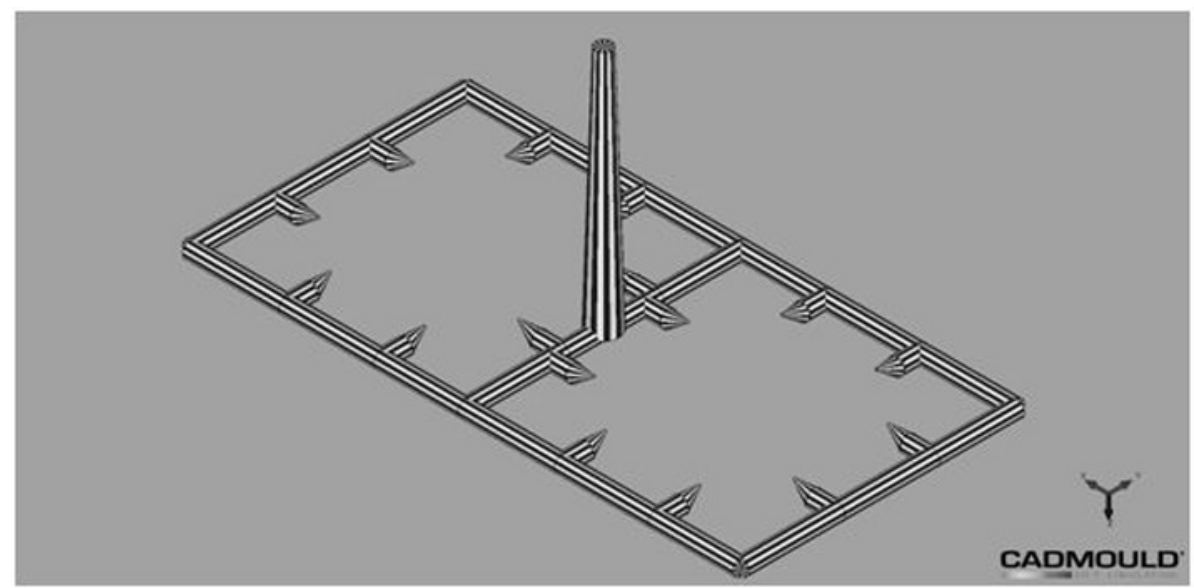

Fig. 3. System of runners created in CADMOULD 3D-F® 


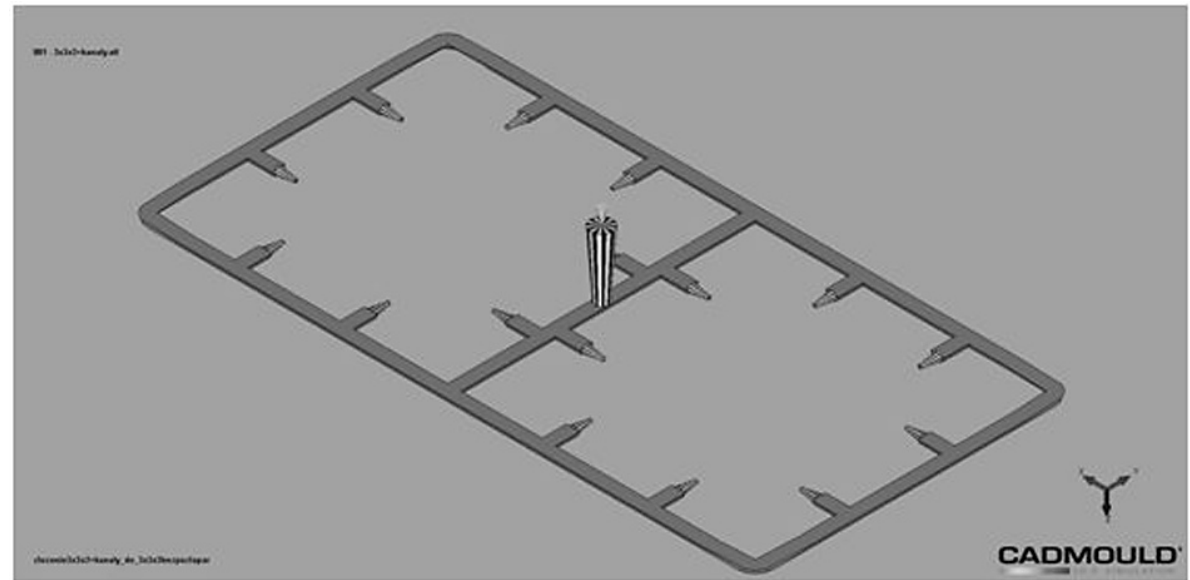

Fig. 4. System of hybrid runners created in CADMOULD 3D-F® and Solid Edge ST10

only a system of runners created in CADMOULD $3 \mathrm{D}-\mathrm{F} \AA$ was applied. The influence of the hybrid joining on the results of the simulation will be analysed in-depth during further research using this program.

\section{Cooling system}

Computer simulations are the starting point for the real production process of puzzles. For this reason, the cooling system (Fig. 5) is similar to the one used in the injection moulding machine in which the injection moulding process is to be performed.

\section{Parameters}

Considering the importance of the reliability of the obtained results, unchangeability of the simulation parameters was assumed. The values of each parameter are shown in the Table 1 . During the simulation of the injection moulding process a digital model of ADSTIF EA648P polypropylene produced by LYONDELLBASELL. The values of the parameters, shown in Table 1, were determined in accordance to the producer's suggestions presented in the technical specification. The only variable parameter was injection time, changing depending on the geometry volume. The values presented in the Table 1 were constant for each simulation process.

\section{FEM mesh}

A mesh convergence test, indicating the optimum value of the mesh density, was conducted for the model. The mesh was selected upon comparing the estimated number of elements of the mesh and time of simulation. Mesh thickness expressed in millimetres determines the field of a single mesh opening. The mesh was applied based on the lateral area, equal $11334 \mathrm{~mm}^{2}$. The $1 \mathrm{~mm}$ thick mesh was deemed as optimal.

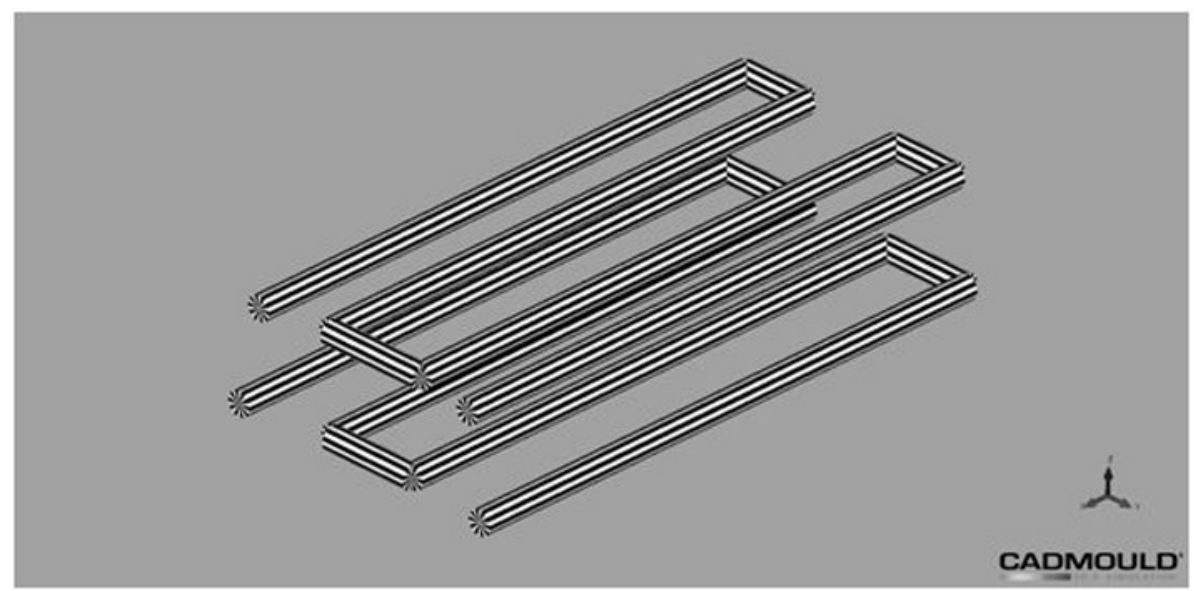

Fig. 5. Cooling system created in CADMOULD 3D-F 
Table 1. Parameters of the process

\begin{tabular}{|l|c|}
\hline \multicolumn{1}{|c|}{ Parameter } & Value \\
\hline Plastification temperature & $225^{\circ} \mathrm{C}$ \\
\hline Temperature of mould walls & $45^{\circ} \mathrm{C}$ \\
\hline Ejection temperature & $100{ }^{\circ} \mathrm{C}$ \\
\hline Injection pressure & $80 \mathrm{MPa}$ \\
\hline Packing pressure & $75 \mathrm{MPa}$ \\
\hline Packing time & $5 \mathrm{~s}$ \\
\hline Cooling time & $15 \mathrm{~s}$ \\
\hline
\end{tabular}

\section{Stages of the puzzle piece evolution based on numerical analyses}

\section{Basic geometry}

In the initial stage a puzzle piece (Fig. 6) of the dimension $50 \times 50 \times 5 \mathrm{~mm}$ with the teeth of hexahedron geometry (dimensions $5 \times 5 \times 5 \mathrm{~mm}$ ). Tooth shape enables the puzzle piece to be joined with another puzzle piece. Due to the specificity of polymer processing the thickness of the element proved to be too significant, which resulted in high values of shrink and deformation. No filling problems were observed, though a significant number of air traps occurred (white cones in Fig. 7). Mean shrink was equal $1.9 \%$. Sink marks, equal over $80 \%$, were marked black in Figure 8. A side effect of using solid parts is a very significant material waste, unjustifiable from the economical point of view. Considering the problems, a hollow geometry was proposed.
Table 2. Comparison of the FEM meshes

\begin{tabular}{|c|c|c|}
\hline $\begin{array}{c}\text { Mesh } \\
\text { thickness }\end{array}$ & $\begin{array}{c}\text { Approximate number of } \\
\text { the mesh elements }\end{array}$ & Simulation time \\
\hline $10 \mathrm{~mm}$ & 1100 & $0.2 \mathrm{~h}$ \\
\hline $5 \mathrm{~mm}$ & 2200 & $0.5 \mathrm{~h}$ \\
\hline $2 \mathrm{~mm}$ & 5500 & $1.0 \mathrm{~h}$ \\
\hline $1 \mathrm{~mm}$ & 11000 & $1.5 \mathrm{~h}$ \\
\hline $0.5 \mathrm{~mm}$ & 22000 & $4.5 \mathrm{~h}$ \\
\hline
\end{tabular}

\section{Hollow geometry}

Hollowing the element resulted in creating a solid open on one side with the wall thickness equal $1.5 \mathrm{~mm}$ (Fig. 9). Despite subtracting some of the material of the puzzle piece it proved more beneficial to thin the walls of the element from $1.5 \mathrm{~mm}$ to $1 \mathrm{~mm}$ (Fig. 9). In both cases no

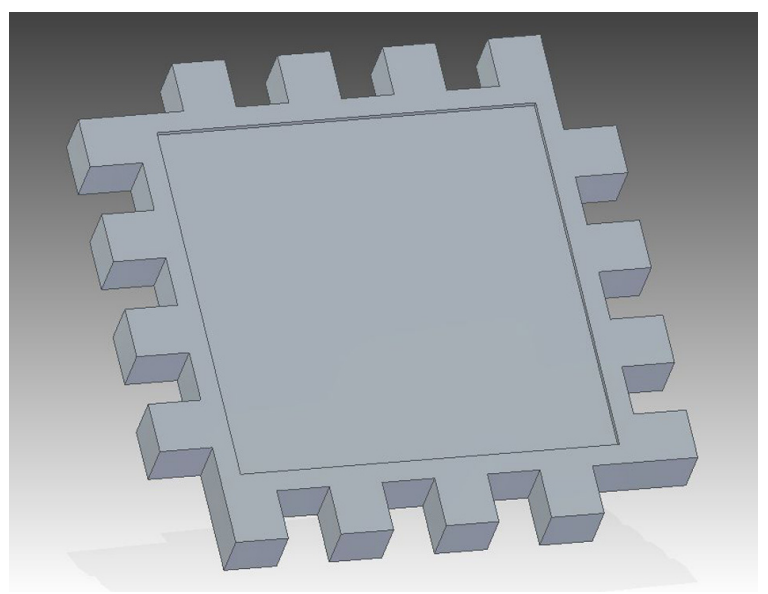

Fig. 6. Model of the dimensions 50x50 mm and thickness $5 \mathrm{~mm}$

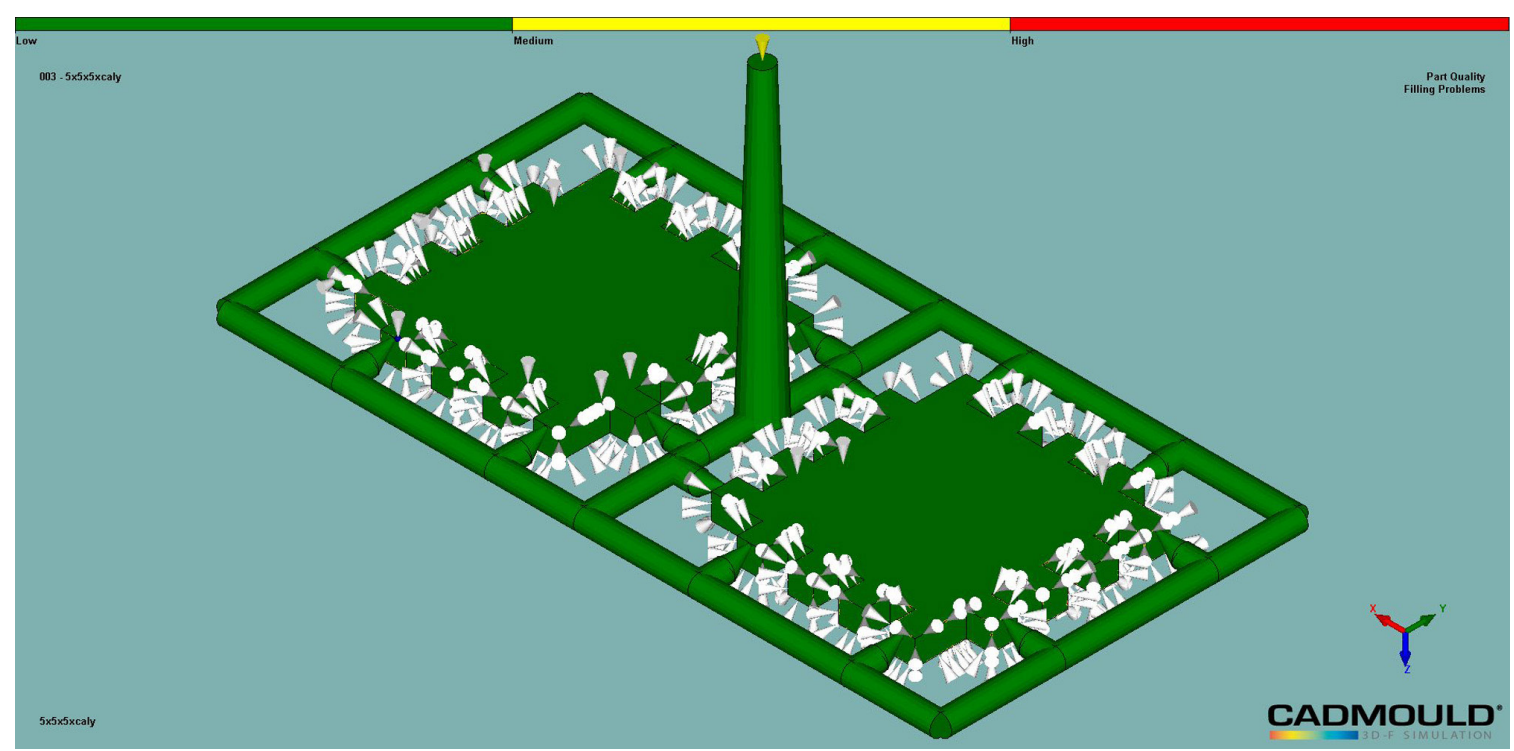

Fig. 7. Filling problem and air traps - base model 


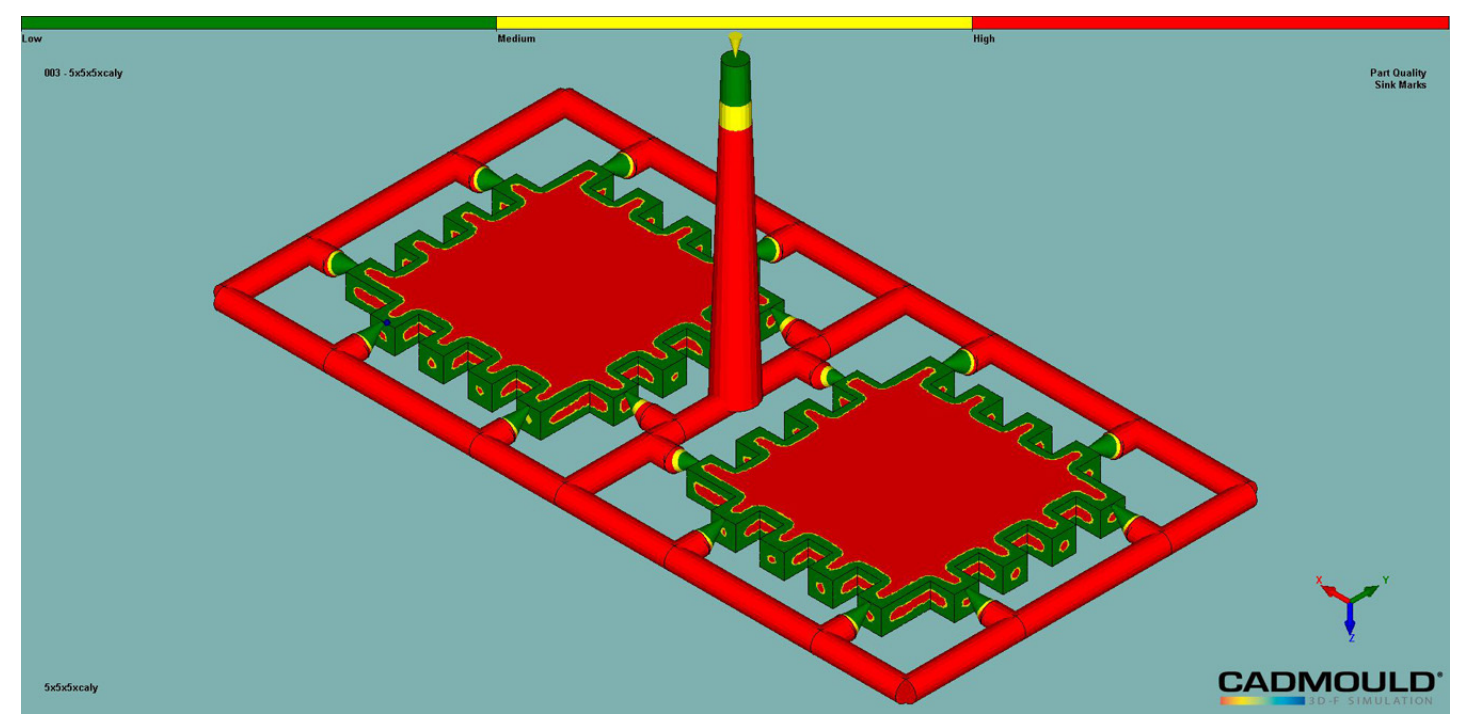

Fig. 8. Sink marks - base model

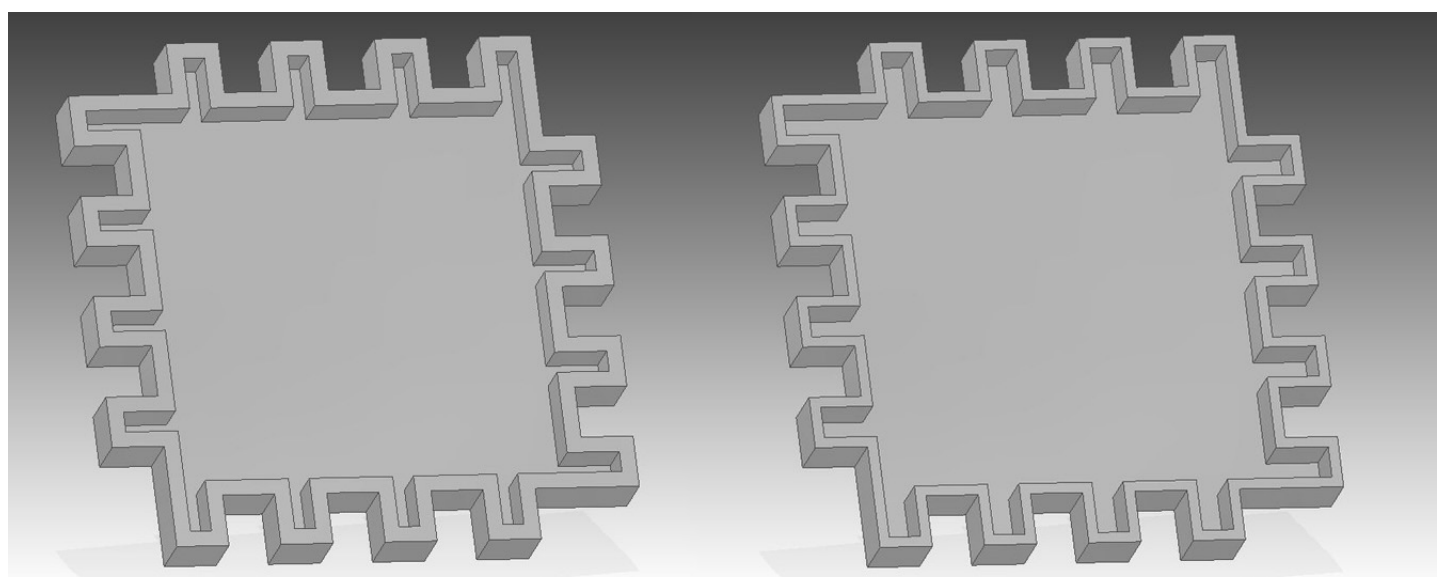

Fig. 9. Hollow model of the dimensions 50x50 mm and wall thickness $1.5 \mathrm{~mm}$ (at left) and hollow model of the dimensions $50 \times 50 \mathrm{~mm}$ and wall thickness $1 \mathrm{~mm}$ (at right)

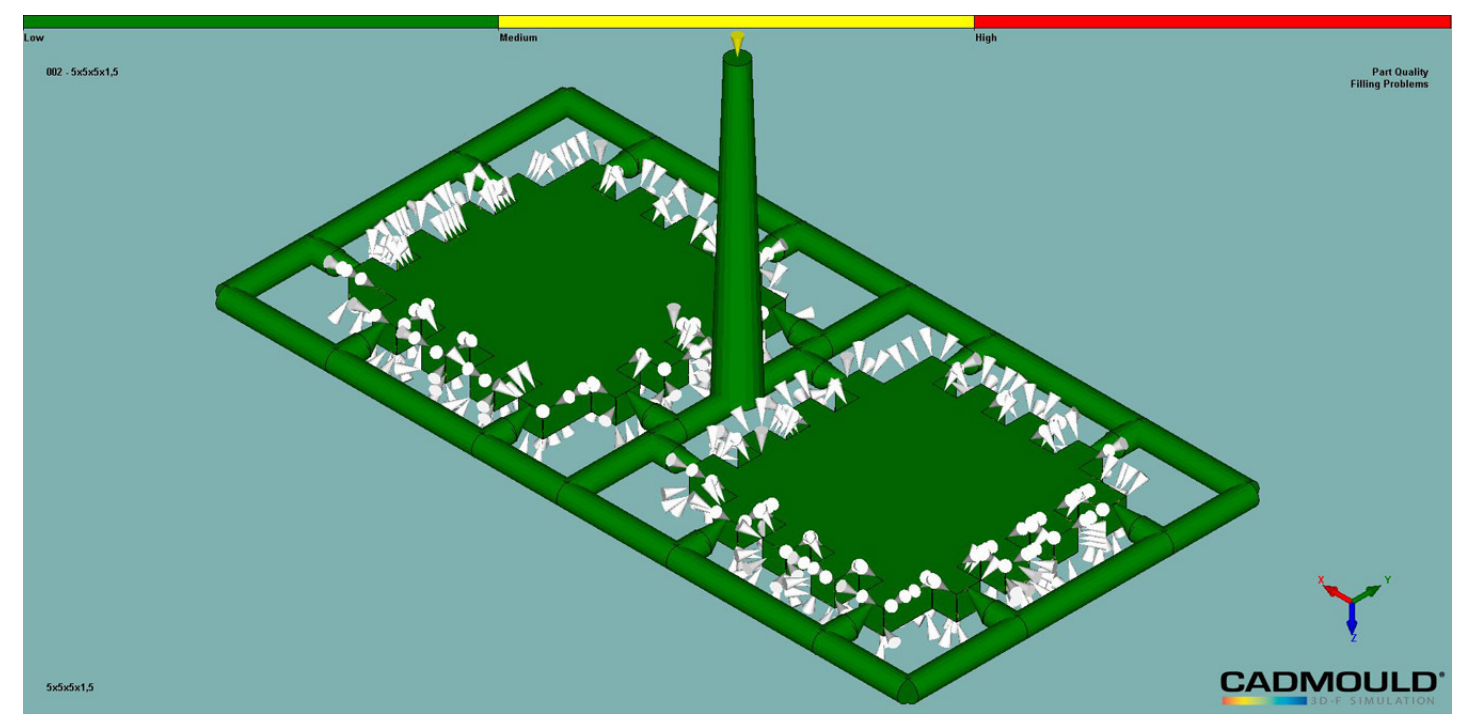

Fig. 10. Filling problem and air traps -hollow model with $1.5 \mathrm{~mm}$ wall thickness 


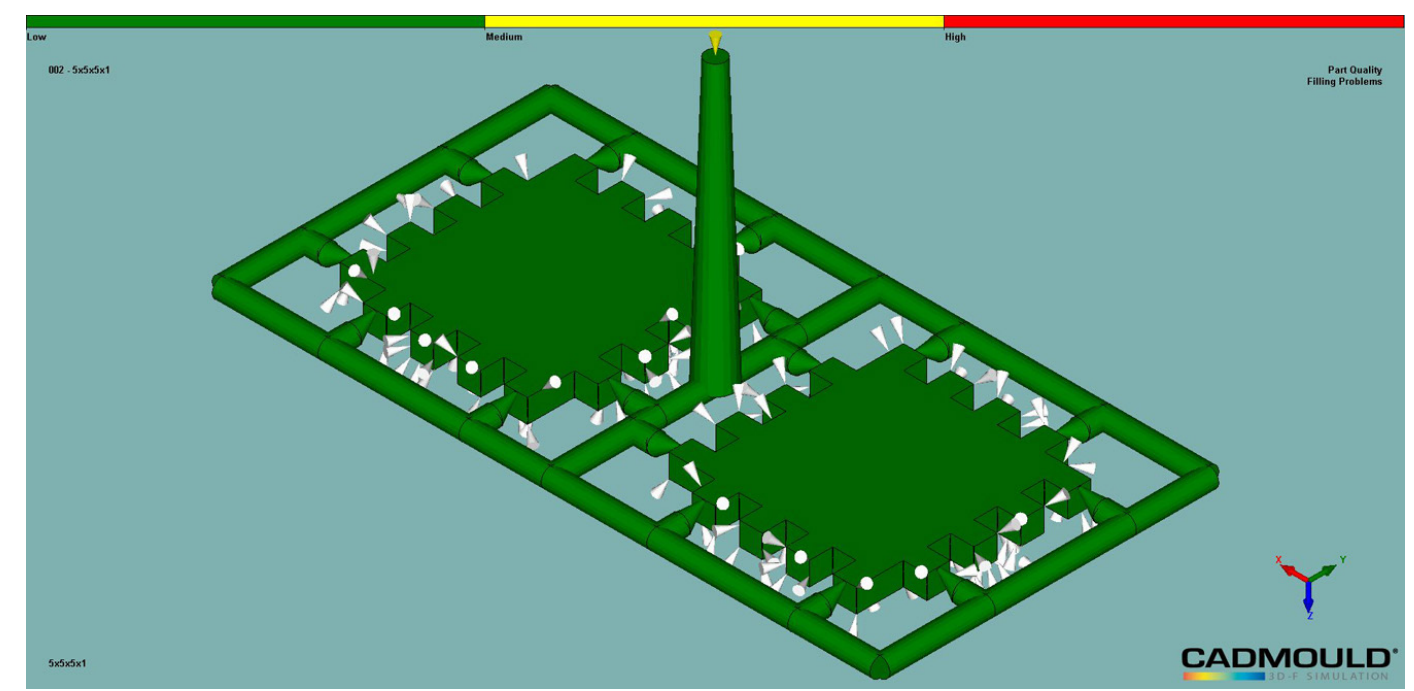

Fig. 11. Filling problem and air traps -hollow model with $1 \mathrm{~mm}$ wall thickness

significant filling problems occurred (Fig. 10 and 11). Mean shrink was equal, respectively $3.4 \%$ for wall thickness $1.5 \mathrm{~mm}$ and $3.5 \%$ for $1 \mathrm{~mm}$. These values express the percentile change to the thickness of the walls. Decreasing thickness of the walls allowed a decrease in the nominal shrink value by $45.7 \%$ :

- $\Delta 1,5=1,5 \mathrm{~mm} * 3,4 \%=0,051 \mathrm{~mm}$

- $\Delta 1=1 \mathrm{~mm} * 3,5 \%=0,035 \mathrm{~mm}$

Upon decreasing the thickness of walls, sink marks increased by 5 percentage points, from $12.3 \%$ to $15.4 \%$, whereas the number of air traps decreased from 595 to 133 . This phenomenon could be caused by a lesser stiffening of the surface by thinner walls or increasing the flat surface of the element, which greatly influences this probability.

\section{Thinned geometry}

On the basis of the obtained results a decrease in the thickness of the element to $3 \mathrm{~mm}$ was proposed. This value seems reasonable in terms of the thickness of polymer elements, since it significantly decreases the problem of shrink [13]. In accordance with the assumption on teeth of the puzzle piece their dimensions were altered (in such a way that the teeth remain cubeshaped). The dimensions of the new puzzle piece are $48 \times 48 \mathrm{~mm}$ and thickness of aforementioned $3 \mathrm{~mm}$ (Fig. 12). Applying a system that allows for screwing/unscrewing a threaded rod with a milled logo necessitated a correction of the shape of the indentation on the puzzle surface.

Such a solution would allow a fast and easy swap of the rod with a milled logo. An additional

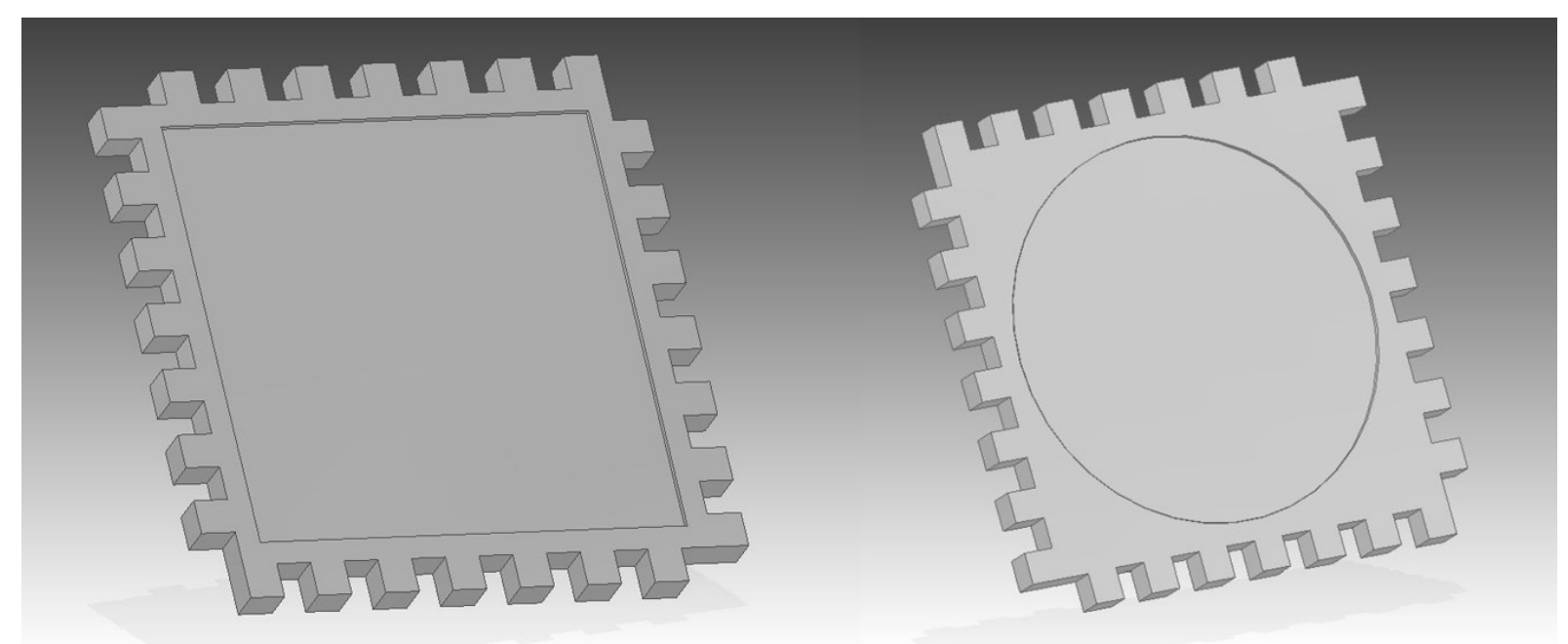

Fig. 12. Model of the dimensions $48 \times 48 \mathrm{~mm}$ and thickness of $3 \mathrm{~mm}$ (at left) and the same model with an indentation for a threaded rod (at right) 
advantage is the possibility of producing a similar rod with a milled logo instead of commissioning a new mould, which increases its utility. Further in the article the results of the computer simulations for each model geometry are presented.

\section{RESULTS}

A summary of the results of the analyses is presented. In order to increase the transparency of the obtained results, the following terminology on geometry was introduced (Table 3 ).

\section{Shrink}

The greatest values of shrink are observed in the base model, which is caused by a significant thickness of the walls (Fig. 13). High values of shrinkf are also caused by the properties of the applied material, which is able to reach the shrink value of over 3\% (Fig. 14).

Table 3. Characteristics of geometric models

\begin{tabular}{|l|c|}
\hline \multicolumn{1}{|c|}{ Type of geometry } & Name \\
\hline $\begin{array}{l}\text { Model with the dimensions } \\
50 \times 50 \mathrm{~mm} \text { and thickness } 5 \mathrm{~mm}\end{array}$ & Basic geometry \\
\hline $\begin{array}{l}\text { Hollow model with the dimensions } \\
50 \times 50 \mathrm{~mm} \text {, height } 5 \mathrm{~mm} \text { and wall } \\
\text { thickness } 1.5 \mathrm{~mm}\end{array}$ & $\begin{array}{c}\text { Hollow geometry } \\
(1.5 \mathrm{~mm})\end{array}$ \\
\hline $\begin{array}{l}\text { Hollow model with the dimensions } \\
50 \times 50 \mathrm{~mm} \text {, height } 5 \mathrm{~mm} \text { and wall } \\
\text { thickness } 1 \mathrm{~mm}\end{array}$ & $\begin{array}{c}\text { Hollow geometry } \\
(1 \mathrm{~mm})\end{array}$ \\
\hline $\begin{array}{l}\text { Model with the dimensions of } \\
48 \times 48 \mathrm{~mm} \text { and thickness } 3 \mathrm{~mm}\end{array}$ & \begin{tabular}{c} 
Thinned geometry \\
\hline
\end{tabular} \\
\hline
\end{tabular}

\section{Deformation}

Deformation of the element means the averaged deviation of the points in geometry in each direction (X, Y and $\mathrm{Z}$ ) for each point of the model (based on FEM mesh). Once again, the best result was achieved in the case of hollow geometry $(1 \mathrm{~mm})$. Thinned geometry has better stiffness and dimensional stability compared to hollow geometry $(1.5 \mathrm{~mm})$. The values of minimum and mean shrink in this case are similar to the values of thinned geometry $(1 \mathrm{~mm})$.

\section{Sink marks and air traps}

The key parameter is sink marks, which successfully indicates overly thick areas, which tend to reach high values of shrink. Decreasing the thickness of the element limited these values. In the case of hollow models ( $1 \mathrm{~mm}$ and $1.5 \mathrm{~mm}$ ) and thinned model sink marks oscillate in the range $14-20 \%$, compared to $83 \%$ for the base model. The lowest value was reached by the hollow model $(1.5 \mathrm{~mm})$ with sink marks equal $14.1 \%$.

Hollow geometry $(1 \mathrm{~mm})$ differs from the other geometries in terms of the number of air traps - approximately 4 to 6 times fewer. Despite such a significant difference, no filling problems were observed.

\section{Mass of the piece and injection time}

Mass of the piece depends directly on the volume of the element. The mass of the element decreases along with its thinning, in the extreme case in over $65 \%$, which is economically advantageous. The average injection time is 0.99 second and in each analysed case the values are similar: from $0.91 \mathrm{~s}$ to $1.07 \mathrm{~s}$.

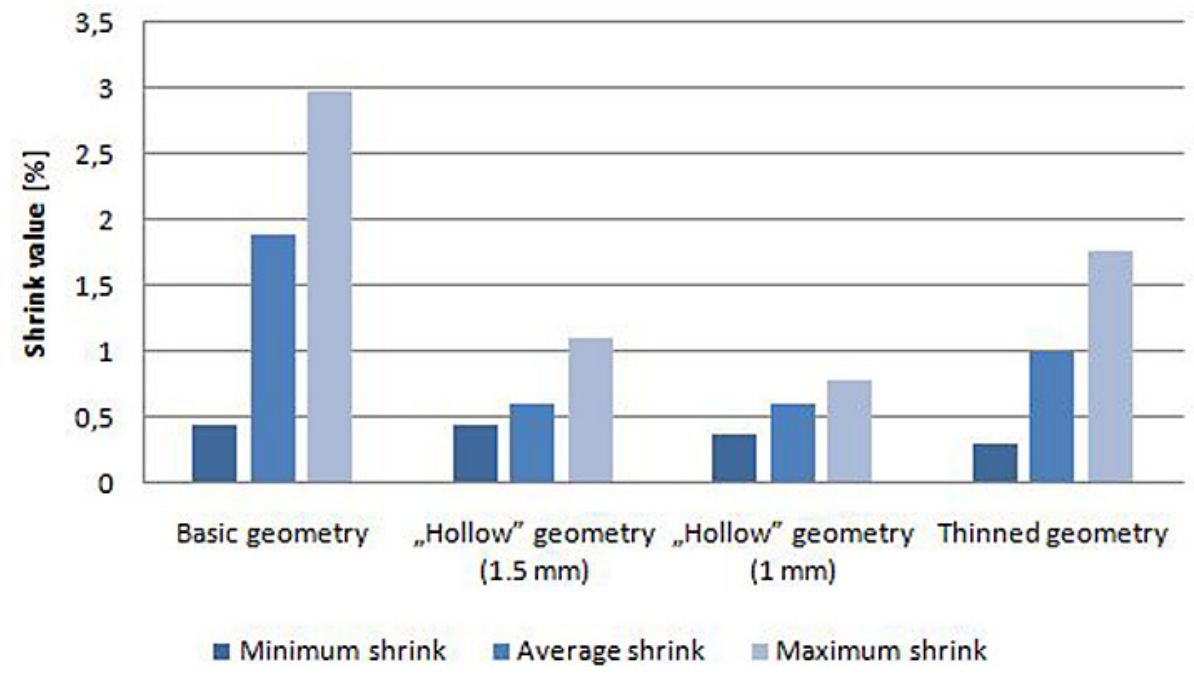

Fig. 13. Comparison of the values of shrink 


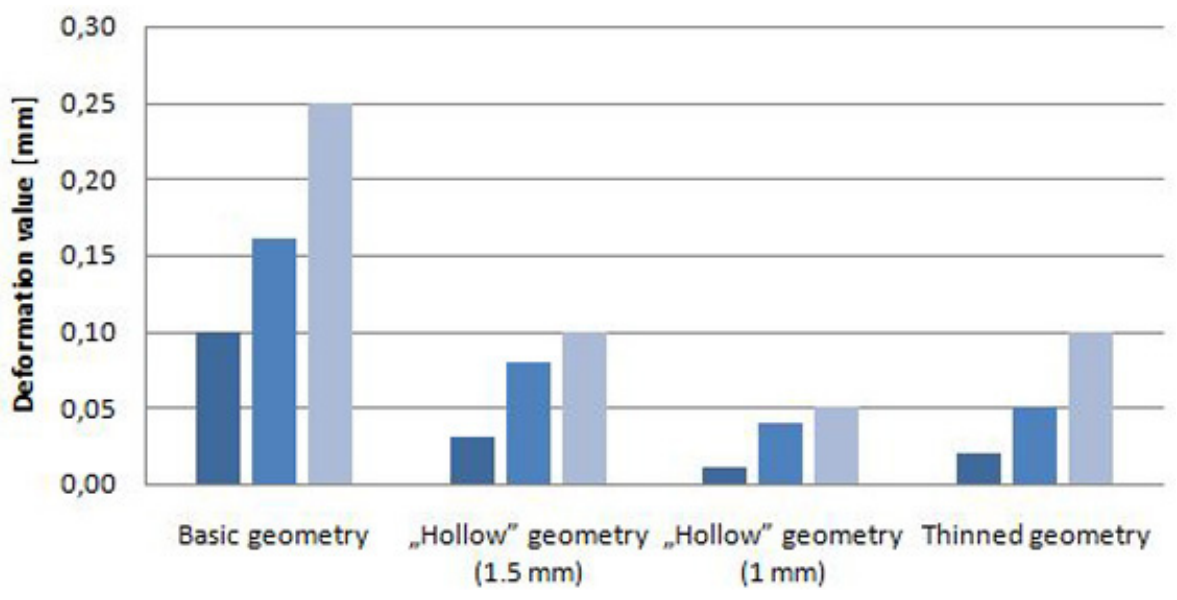

Minimum deformation $\quad$ Average deformation Maximum deformation

Fig. 14. Comparison of the values of deformation for the analysed models

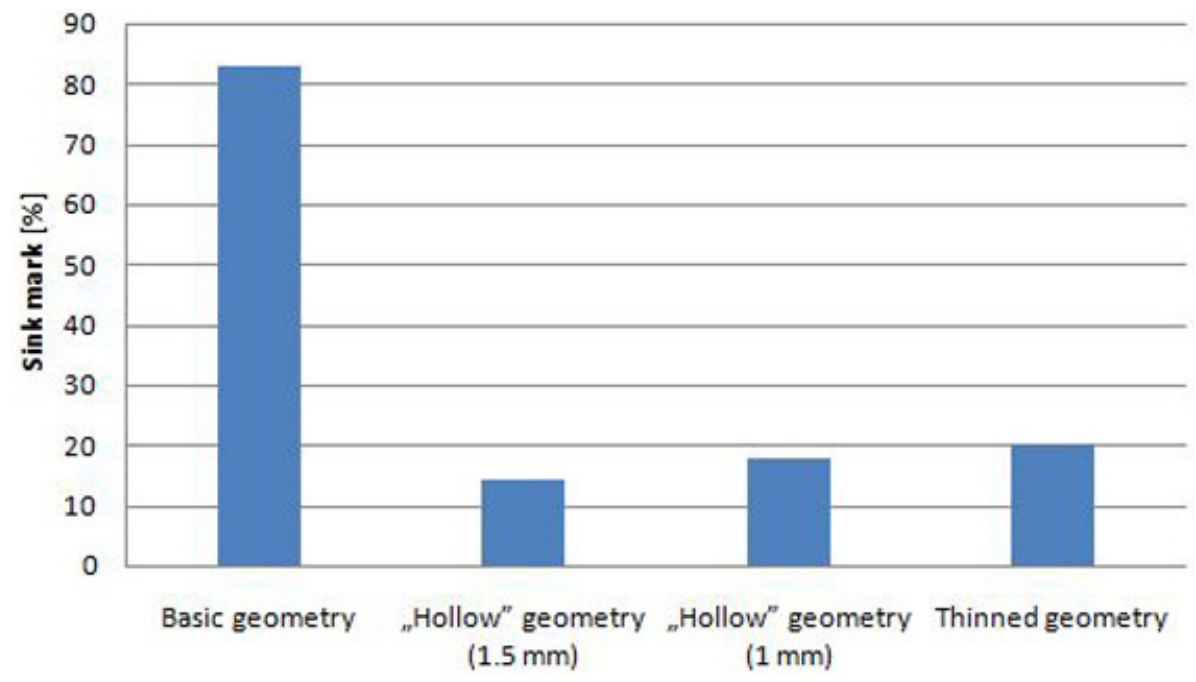

Fig. 15. Comparison of the values of sink marks

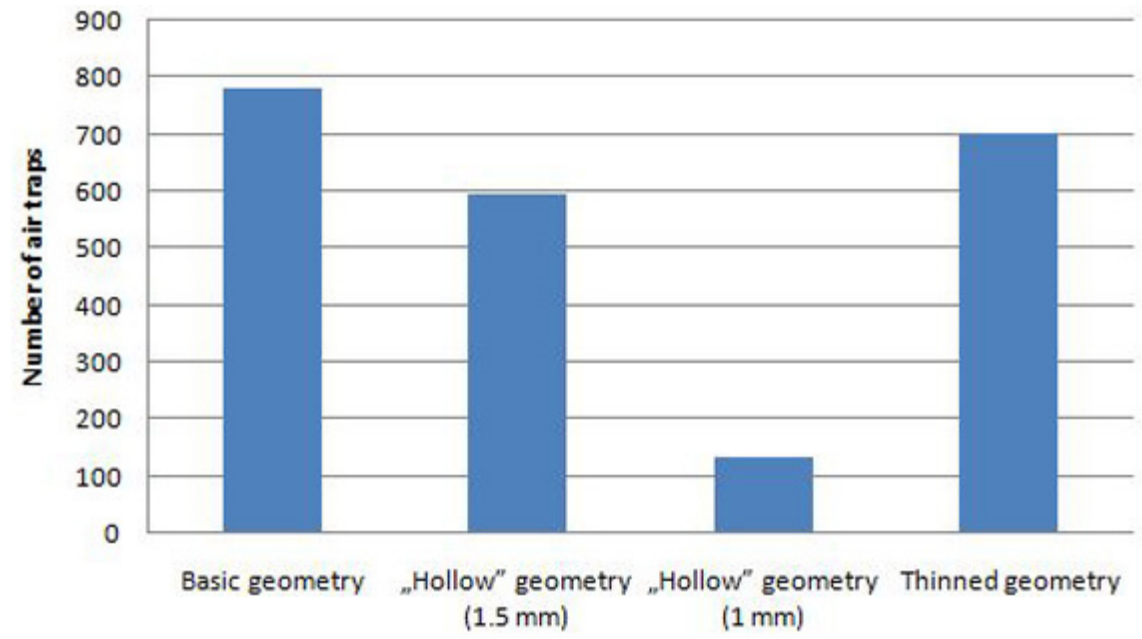

Fig. 16. Comparison of the quantity of air traps 


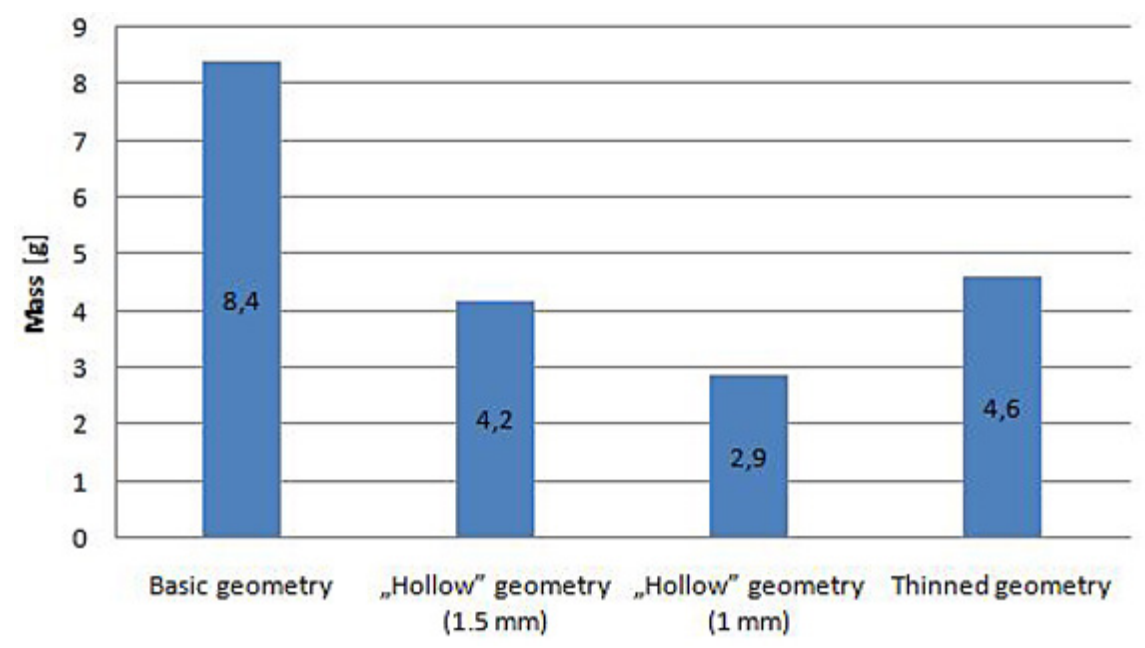

Fig. 17. Comparison of mass for the analysed models

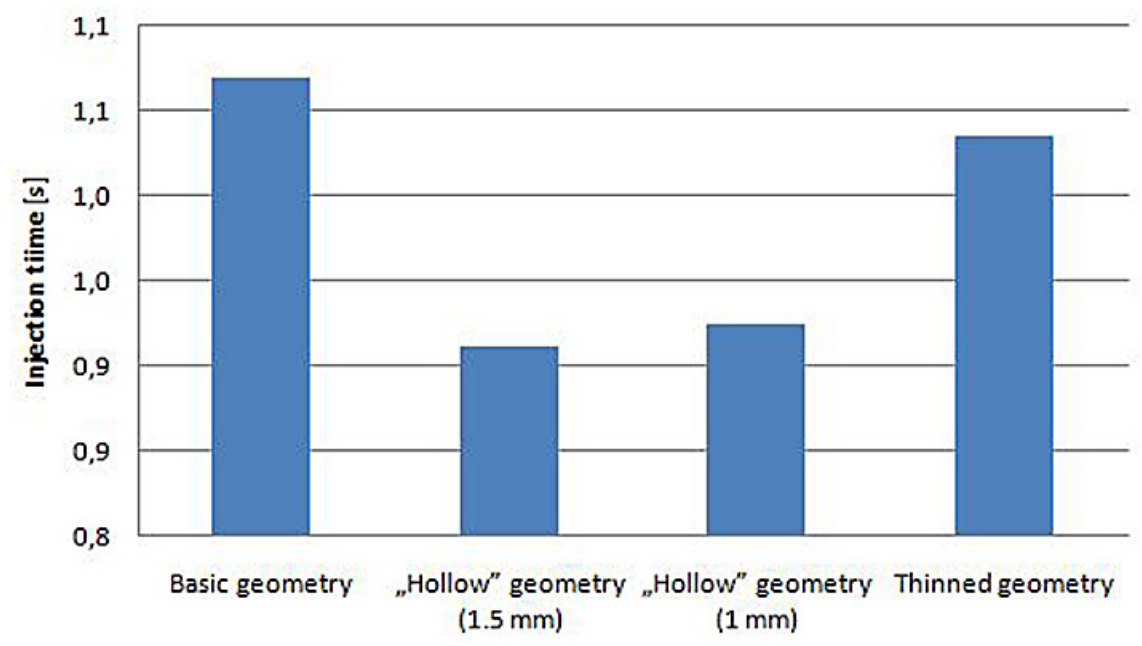

Fig. 18. Comparison of injection time for the analysed models

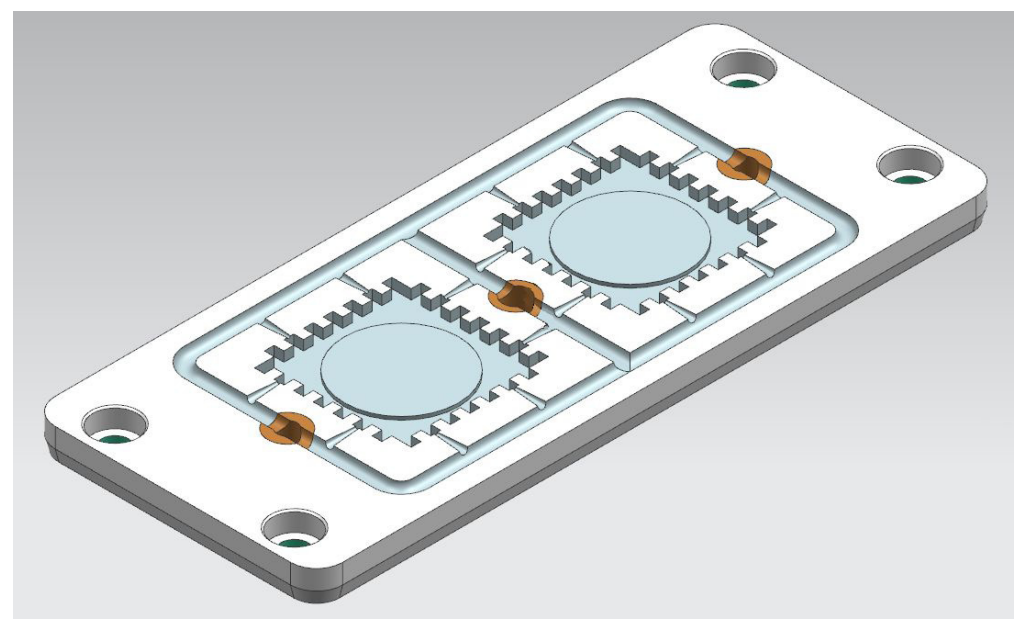

Fig. 19. Visualisation of the mold 
Due to the smaller mass, injection time should decrease. In the case of the model with the smallest mass (hollow geometry $1 \mathrm{~mm}$ ), however, a problem with material flow might occur in 1 and $1.5 \mathrm{~mm}$ thick cavity walls. In the case of the base and thinned models material flow is easier.

\section{CONCLUSIONS}

Computer simulation is powerfull tool that helps in optimization of geomertry or process parameters. Due to reduction of time it helps to hast process of modelling and prototyping. Furthermore, simulation allow to prepare comparison of vary combination of model with variable or invariable parameters what can be impossible in real process.According to the performednumerical analyses, the hollow geometry $(1 \mathrm{~mm})$ obtained the best values of the considered parameters, both for shrink, deformation, sink marks and air traps. However, due to the risk of the part shrinking on the rod and ejection problems, thinned geometry was deemed the most favourable. In its case, the values of the sink marks was reduced by nearly four times, schrink by at least $50 \%$, and deformation of part dropped by $40 \%$ in comparison to baisic model. FEM thickness affected in precision of results but there was no relevant diference between each kind of mesh thus as optimal one was choosen $2 \mathrm{~mm}$ thick. This type of mesh have best balance between accuracy of results and simulation time. Choosing mesh with greater number of elements cause just enlogation of simulation time without improvement of results quality. A model of an insert for the injection mould was designed on the basis of the obtained results. The real model will be experimentally verified. In the further studies a comparison of the results of numerical analysis and real experiments will be carried out.

\section{REFERENCES}

1. Barker R.M., Cox M.G., Forbes A.B. and Harris P.M.: Discrete Modelling and Experimental Data Analysis, version 2.0,Software Support for Metrology Best Practice Guide No. 4, Centre for Mathematics and Scientific Computing, 2004.

2. Blair K.: General Design Principles for DuPont Engineering Polymers, DuPont Engineering Polymers, Midland, 2000.
3. Ledder G.: Mathematics for the Life Sciences: Calculus, Modeling, Probability, and Dynamical Systems, Springer Science, Berlin, 2013.

4. Muciek A.: Wyznaczanie modeli matematycznych z danych eksperymentalnych, Oficyna Wydawnicza Politechniki Wrocławskiej, Wrocław 2012.

5. Sikora R., Garbacz T.: Przetwórstwo tworzyw polimerowych cz.1, Politechnika Lubelska Lublin, 2012.

6. Gould H., Tobochnik J. and Christian W.:An introduction to computer simulation methods: applications tophysical systems-3rd Edition, Pearson Addison Wesley, 2007.

7. Gajdoš I., Jachowicz T., Slota J. and Krasinskyi $\mathrm{V}$ : Interpretation of warpage simulation results in ASMI. Applied Computer Science, 11(2), 2015, 5-16.

8. Iwko J. and Steller R.: Polymer plastification during injection molding, International Polymer Processing Journal of the Polymer Processing Society XXIII, 2008, 252-262.

9. Jachowicz T., Gajdoš I. and Krasinskyi V.: Research on the content and filler type on injection shrinkage. Advances in Science and Technology Research Journal 8(23), 2014, 6-13.

10. Kowalska B.: Skurcz wtryskowy a zależność p-v-T, Polimery - tom $52 \mathrm{nr}$ 4,Instytut Chemii Przemysłowej, 2007, 280-285.

11. Łatuszyńska M.: Metody symulacji komputerowejpróba klasyfikacji logicznej, Studies\&Proceedings of PolishAssociation for Knowledge Management $\mathrm{Nr}$ 41, 2011, 163-176.

12. Frącz W.: Optymalizacja skurczu wyprasek z wykorzystaniem wyników symulacji 3D, Zeszyty Naukowe Politechniki Rzeszowskiej Nr 279, Mechanika z. 83 (4/11), 2011, 11-23.

13. Mańko P. and Jachowicz T.: Zastosowanie symulacji numerycznych przy projektowaniu wyprasek wtryskowych elementów wyposażenia taktycznego, Nowoczesne materiały i technologie w technikach wytwarzania, Prefekta Info Lublin, 2017, 98-127.

14. Mikielewicz J.: Zasady formułowania modeli matematycznych zjawisk cieplno-przepływowych, Journal of Power Technologies, Vol 84, 1996, 1-15.

15. PlasticsEurope: Tworzywa sztuczne - Fakty 2017 Analiza produkcji, zapotrzebowania oraz odzysku tworzyw sztucznych w Europie, 2017, access: 14.03.2019.

16. PlasticsEurope: Tworzywa sztuczne - fascynujący materiał, 2015, access: 14.03.2019.

17. Sargent R.G.: Verification and validation of simulation models, Proceedings of the 2011 Winter Simulation Conference (WSC), Phoenix, 2011, 183-198. 